\title{
Analysis of prognostic factors affecting mortality in Fournier's gangrene: A study of 72 cases
}

\author{
Mohamed Tarchouli, MD; ${ }^{*}$ Ahmed Bounaim, MD; ${ }^{*}$ Mohamed Essarghini, MD; ${ }^{*}$ Moulay Brahim Ratbi, MD; \\ Mohamed Said Belhamidi, MD; ${ }^{*}$ Abdelhak Bensal, MD; ${ }^{*}$ Adil Zemmouri, MD; ${ }^{\dagger}$ Abdelmounaim Ait Ali, MD; \\ Khalid Sair, MD*
}

*Department of Digestive Surgery, Mohammed V Military Hospital, Faculty of Medicine and Pharmacy, Mohammed V University, Rabat, Morocco; ${ }^{\dagger}$ Department of Anesthesiology and Intensive Care, Mohammed V Military Hospital, Faculty of Medicine and Pharmacy, Mohammed V University, Rabat, Morocco

Cite as: Can Urol Assoc J 2015;9(11-12):E800-4. http://dx.doi.org/10.5489/cuaj.3192 Published online November 4, 2015.

\section{Abstract}

Introduction: Fournier's gangrene is a rapidly progressing necrotizing fasciitis of the perineum and genital area associated with a high mortality rate. We presented our experience in managing this entity and identified prognostic factors affecting mortality.

Methods: We carried out a retrospective study of 72 patients treated for Fournier's gangrene at our institution between January 2005 and December 2014. Patients were divided into survivors and nonsurvivors and potential prognostic factors were analyzed.

Results: Of the 72 patients, 64 were males (89\%) and 8 females $(11 \%)$, with a mean age of 51 years. The most common predisposing factor was diabetes mellitus (38\%). The mortality rate was $17 \%$ (12 patients died). Statistically significant differences were not found in age, gender, and predisposing factors, except in heart disease $(p=0.038)$. Individual laboratory parameters significantly correlating with mortality included hemoglobin $(p=0.023)$, hematocrit $(p=0.019)$, serum urea $(p=0.009)$, creatinine $(p=0.042)$, and potassium $(p=0.026)$. Severe sepsis on admission and the extent of affected surface area also predicted higher mortality. Others factors, such as duration of symptoms before admission, number of surgical debridement, diverting colostomy and length of hospital stay, did not show significant differences. The median Fournier's Gangrene Severity Index (FGSI) was significantly higher in non-survivors $(p=0.002)$.

Conclusion: Fournier's gangrene is a severe surgical emergency requiring early diagnosis and aggressive therapy. Identification of prognostic factors is essential to establish an optimal treatment and to improve outcome. The FGSI is a simple and valid method for predicting disease severity and patient survival.

\section{Introduction}

Fournier's gangrene is a rapidly progressive necrotizing fasciitis of the perineal, perianal and genital area, first described by the French dermatologist Jean-Alfred Fournier in $1883 .^{1}$ He described a fulminant gangrene of the scrotum and penis observed especially in healthy young men without apparent etiologic factors. Presently, the disease mainly affects men in the fifth to seventh decades of life, with associated predisposing factors and an identifiable etiology. The gangrene is considered the result of a polymicrobial aerobic and anaerobic synergistic infection originating from a colorectal, genitourinary or skin infection site. It can progress to a fulminant soft tissue infection and spread rapidly along the fascial planes to the abdominal wall and even the thorax.

Early diagnosis with fast and adequate treatment, including aggressive surgical debridement, hemodynamic stabilization and broad-spectrum antibiotic-therapy, are the mainstay of successful management. However, despite advances in surgical technique and critical care, the mortality rate is still high, between $20 \%$ and $50 \%$ in most contemporary series. ${ }^{2}$

In this study, we presented our experience in managing Fournier's gangrene during a 10-year period and we analyzed different factors affecting its outcome and mortality.

\section{Methods}

We conducted a retrospective study of 72 patients diagnosed with Fournier's gangrene and undergoing surgical treatment at Mohammed V Military Hospital of Rabat, Digestive Surgery Department, Morocco during the 10-year period between January 2005 and December 2014. The diagnosis was based on the patient's medical history and physical examination. Data were collected for age, gender, etiology, risk factors, duration of symptoms before admission, physical examination, laboratory findings, total extent of affected body surface, antibiotic therapy, surgical treatment and number of subsequent debridement, requirement for intestinal diversion, length of hospital stay, and outcome. Mortality was defined as disease-related death during the hospital stay. Patients with incomplete medical records were excluded from the study. 
The extent of gangrene was measured using nomograms routinely used to assess the extent of burn injuries, according to which penis, scrotum and perineum each account for $1 \%$ surface area, and each ischiorectal fossa accounts for $2.5 \% .^{3,4}$

To assess the severity of infection, we used the Fournier's Gangrene Severity Index (FGSI) described by Loar and colleagues in 1995, and the presence of sepsis, severe sepsis or septic shock on admission. FGSI was obtained by combining admission clinical (temperature, heart and respiratory rates) and laboratory parameters (hematocrit and leukocyte count, serum sodium, potassium, creatinine and bicarbonate). ${ }^{5}$ In this index, each parameter is given 0 to 4 points, and FGSI is calculated by adding the points of each parameter. The cut-off point is 9, meaning that when FGSI is $>9$, the probability of death is $75 \%$, and when it is $\leq 9$, the probability of survival is $78 \%$ (Table 1). Sepsis is defined as infection with systemic inflammatory response syndrome, which is manifested with two or more of the following findings: body temperature $<36{ }^{\circ} \mathrm{C}$ or $>38{ }^{\circ} \mathrm{C}$, heart rate $>90$ beats $/ \mathrm{min}$, respiratory rate $>20$ breaths/ $\mathrm{min}$ or $\mathrm{PaCO} 2<32 \mathrm{mmHg}$, and leukocyte count $>12000$ cells $/ \mathrm{mm}^{3},<4000$ cells $/ \mathrm{mm}^{3}$, or $>10 \%$ of immature forms. Severe sepsis is defined as sepsis combined with organ dysfunction, hypotension or tissue hypoperfusion. Septic shock is defined as sepsis with refractory arterial hypotension or signs of systemic hypoperfusion in spite of fluid resuscitation. ${ }^{3,4}$

Statistical analysis was performed using SPSS program version 13.0. Qualitative variables were defined by frequency and percentage, and quantitative variables were defined by the median value and the 25 th to 75 th percentiles. The statistical tests employed in the univariate analysis were the chi-square test and Fisher's exact test for the qualitative variables and the Mann-Whitney test for the quantitative variables. Statistical significance was set at $p<0.05$.

\section{Results}

Of the 72 patients, 64 were males (89\%) and 8 were females $(11 \%)$, with a median age of 51 years (range: $23-75)$, and a medical history of Fournier's gangrene in $49(68 \%)$ patients. Diabetes mellitus coexisted in 27 patients (38\%), high blood pressure in $21(29 \%)$, heart disease in $16(22 \%)$, lung disease in $5(7 \%)$, liver disease in $6(8 \%)$, kidney disease in $8(11 \%)$, and vascular disease in 10 (14\%). Nine patients (13\%) presented immunodepression with 5 malignant neoplasms, 2 chemotherapeutic treatments, and 2 chronic corticosteroid use. Chronic alcoholism was detected in 4 patients $(6 \%)$ and smoking habit in 14 patients (19\%).

An etiological factor was identified in 67 (93\%) cases; therefore, only $5(7 \%)$ patients had idiopathic Fournier's gangrene. The most common source of sepsis was anorectal, especially anal suppurations. No statistical significant difference in etiologic factor was found between survivors and non-survivors (Table 2).

The most common clinical signs at the time of admission were perineal necrosis $(n=67 ; 93 \%)$, perineal pain $(\mathrm{n}=61 ; 85 \%)$, fever $(\mathrm{n}=38 ; 53 \%)$, and poor general condition $(\mathrm{n}=27 ; 38 \%)$. All patients underwent wide debridement of necrotic tissue under the cover of broad spectrum antibiotics (Fig. 1). Treatment was continued with sequential debridement until the wound showed healthy granulation tissue. Intestinal diversion and hyperbaric oxygen therapy were applied, in addition to surgical debridement when required. Therefore, adjunctive hyperbaric oxygen therapy was used in 56 patients $(78 \%)$ and prevention of fecal contamination was attempted by diverting-colostomy in 14 patients (19\%). Patients with severe sepsis, requiring vasopressors or mechanical ventilation support were treated in the intensive care unit.

Of the 72 patients, 60 (83\%) survived and $12(17 \%)$ died. The etiology in mortality cases was colorectal in 7 cases $(13 \%)$, genitourinary in $3(38 \%)$, traumatic in $2(50 \%)$. The

Table 1. Fournier's Gangrene Severity Index

\begin{tabular}{|c|c|c|c|c|c|c|c|c|c|}
\hline \multirow{2}{*}{ Variables } & \multicolumn{4}{|c|}{ High abnormal values } & \multicolumn{5}{|c|}{ Low abnormal values } \\
\hline & +4 & +3 & +2 & +1 & 0 & +1 & +2 & +3 & +4 \\
\hline Temperature, ${ }^{\circ} \mathrm{C}$ & $>41$ & $39-40.9$ & - & $38.5-38.9$ & $36-38.4$ & $34-35.9$ & $32-33.9$ & $30-31.9$ & $<29.9$ \\
\hline Heart rate & $>180$ & $140-179$ & $110-139$ & - & 70-109 & - & $55-69$ & $40-54$ & $<39$ \\
\hline Respiration rate & $>50$ & $35-49$ & - & $25-34$ & $12-24$ & $10-11$ & $6-9$ & - & $<5$ \\
\hline Serum $\mathrm{Na}, \mathrm{mmol} / \mathrm{L}$ & $>180$ & $160-179$ & $155-159$ & $150-154$ & $130-149$ & - & $120-129$ & $111-119$ & $<110$ \\
\hline Serum K, mmol/L & $>7$ & $6-6.9$ & - & $5.5-5.9$ & $3.5-5.4$ & $3-3.4$ & $2.5-2.9$ & - & $<2.5$ \\
\hline $\begin{array}{l}\text { Serum creatinine, } \mathrm{mg} / 100 \mathrm{ml} \text {, } \\
\times 2 \text { for acute renal failure }\end{array}$ & $>3.5$ & $2-3.4$ & $1.5-1.9$ & - & $0.6-1.4$ & - & $<0.6$ & - & - \\
\hline Hematocrit, \% & $>60$ & - & $50-59.9$ & $46-49.9$ & $30-45.9$ & - & $20-29.9$ & - & $<20$ \\
\hline $\begin{array}{l}\text { White blood cell count, } \\
\times 1000 / \mathrm{mm}^{3}\end{array}$ & $>40$ & - & 20-39.9 & $15-19.9$ & $3-14.9$ & - & $1-2.9$ & - & $<1$ \\
\hline Serum bicarbonate, $\mathrm{mmol} / \mathrm{L}$ & $>52$ & $41-51,9$ & - & $32-40.9$ & $22-31.9$ & - & $18-21.9$ & $15-17.9$ & $<15$ \\
\hline
\end{tabular}


Tarchouli et al.

\begin{tabular}{lc}
\hline Table 2. Sources of Fournier's gangrene \\
\hline Etiology & Patients (n) (\%) \\
\hline Colorectal & $54(75 \%)$ \\
Genitourinary & $8(11 \%)$ \\
Retroperitoneal (psoas abscess) & $1(1 \%)$ \\
Traumatic & $4(6 \%)$ \\
Unknown & $5(7 \%)$ \\
\hline
\end{tabular}

causes of death were: multiple organ failure in 10 (83\%), acute myocardial infarction in 1 and pulmonary thromboembolism in 1. Microbiological cultures were done in 44 patients $(61 \%)$. A single microorganism was isolated in 7 patients $(16 \%)$, and multiple microorganisms were found in 37 patients $(84 \%)$. The most frequent bacterial agents cultured from the necrotic tissue were Escherichia coli (83\%) and Streptococcus spp (35\%). Analyses of different prognostic factors according to survivors and non-survivors are shown in Table 3 and Table 4.

\section{Discussion}

In the past, Fournier's gangrene was thought to affect young men only. Currently, the reported age of patients has progressively increased, as was shown in our study with a median age of 51..$^{6,7}$ Some authors do not report significant differences of age between survivors and non-survivors. ${ }^{7,8}$ Conversely, a growing number of studies show that surviving patients were significantly associated with a younger age..$^{9,10}$ The same was true in our series, but without statistical significance. With regard to gender, male predominance has also been reported in previous studies. ${ }^{11}$ Czymek and colleagues described the female gender as a risk factor associated with a higher mortality; however, we could not demonstrate similar findings. ${ }^{12}$

Despite the development of treatment modalities, antibiotic therapy, and intensive care techniques, Fournier's gangrene is still a fatal disease with high mortality rate $(20 \%-50 \%) .{ }^{3,13,14} \mathrm{~A}$ mortality rate of $17 \%$ was detected at our centre, that is $14 \%(8 / 56)$ in the hyperbaric oxygen therapy group and $25 \%(4 / 16)$ in the non-hyperbaric oxygen therapy group. Our good results may be explained by the relative young age of our patients and especially the improvement of treatment options (adjunctive hyperbaric oxygen therapy to radical surgical debridement, regularly wound debridement and dressings, and broad spectrum antibiotic coverage). Hyperbaric oxygen therapy is particularly helpful in increasing oxygen tension in infected tissue and in killing anaerobic bacteria limiting the extent of necrosis and improving wound healing. ${ }^{6}$

Multiple predisposing factors for Fournier's gangrene include diabetes mellitus, arterial hypertension, chronic renal failure, systemic disorders, malignant neoplasms, chronic alcoholism, immunosuppression, and local trau-

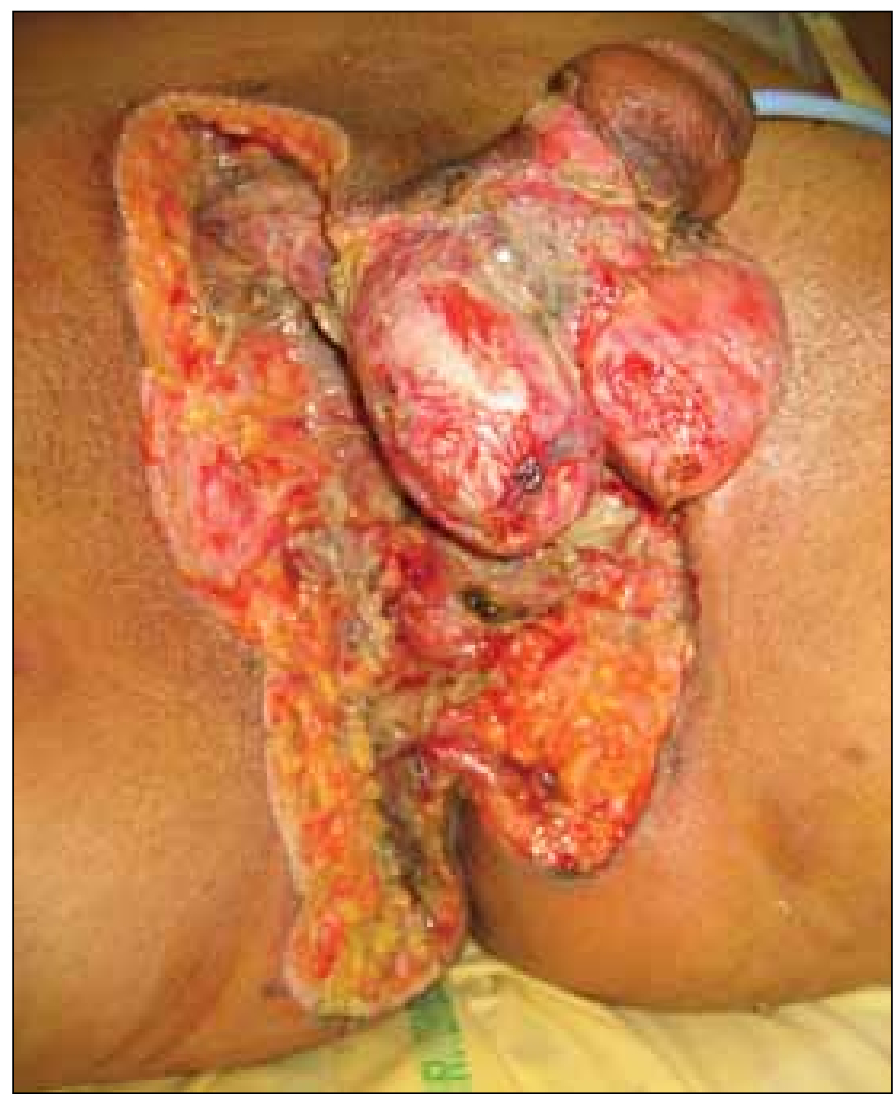

Fig.1. Fournier's gangrene located to the perineum and scrotum after surgical debridement.

ma. ${ }^{15,16}$ These conditions are associated with reduced cellmediated immune response, which favours the development of the infection. Some authors have reported an association between these predisposing factors and mortality. ${ }^{17,18}$

Table 3. Analysis of prognostic factors (qualitative variables)

\begin{tabular}{lccc}
\hline Variables & $\begin{array}{c}\text { Survivors } \\
\text { (n= 60) } \mathbf{n}(\%)\end{array}$ & $\begin{array}{c}\text { Non-survivors } \\
(\mathbf{n}=\mathbf{1 2}) \mathbf{n}(\%)\end{array}$ & $\boldsymbol{p}$ value \\
\hline Male/female & $54 / 6$ & $10 / 2$ & NS \\
Diabetes & $20(33.3)$ & $7(58.3)$ & NS \\
Hypertension & $16(26.7)$ & $5(41.7)$ & NS \\
Heart disease & $8(13.3)$ & $8(66.7)$ & 0.038 \\
Lung disease & $4(6.7)$ & $1(8.3)$ & NS \\
Liver disease & $5(8.3)$ & $1(8.3)$ & NS \\
Kidney disease & $6(10.0)$ & $2(16.7)$ & NS \\
vascular disease & $8(13.3)$ & $2(16.7)$ & NS \\
Malignant disease & $2(3.3)$ & $3(25.0)$ & NS \\
Severe sepsis on & $6(10.0)$ & $9(75.0)$ & 0.027 \\
admission & & & \\
Septic shock on & $0(0.0)$ & $2(16.7)$ & NS \\
admission & $10(16.7)$ & $4(33.3)$ & NS \\
Diverting colostomy & & & \\
\hline NS: nonsignifict $p>0.05)$ & & &
\end{tabular}

NS: nonsignificant $(p>0.05)$ 


\begin{tabular}{|c|c|c|c|}
\hline Variables & $\begin{array}{c}\text { Survivors (min, } \\
\text { max) } \\
(n=60)\end{array}$ & $\begin{array}{l}\text { Non-survivors } \\
\text { (min, max) } \\
(n=12)\end{array}$ & $\begin{array}{c}p \\
\text { value }\end{array}$ \\
\hline Age & $50(40,59)$ & $63(51,70)$ & NS \\
\hline Heart rate, bpm & $88(80,103)$ & $91(81,112)$ & NS \\
\hline Respiration rate, rpm & $19(17,21)$ & $20(18,22)$ & NS \\
\hline Temperature, ${ }^{\circ} \mathrm{C}$ & $37.7(37.0,38.4)$ & $38.6(36.6,39.0)$ & NS \\
\hline Hemoglobin, (g/dL) & $13(10.5,14.1)$ & $10.8(8.6,12.0)$ & 0.023 \\
\hline Hematocrit, \% & $38.2(30.4,41.1)$ & $30.4(27.1,35)$ & 0.019 \\
\hline $\begin{array}{l}\text { White blood cell } \\
\text { count, } 103 \text { cells } / \mathrm{mm}^{3}\end{array}$ & $15.7(14.3,21.5)$ & $22.8(15.6,33.1)$ & NS \\
\hline Urea & $57(36,74)$ & $103(86,147)$ & 0.009 \\
\hline Creatinine, mg/dL & $1.2(1.0,1.7)$ & $1.8(1.1,4.5)$ & 0.042 \\
\hline Sodium, mmol/L & $134(131,136)$ & $135(129,138)$ & NS \\
\hline Potassium, $\mathrm{mmol} / \mathrm{L}$ & $3.8(3.5,4.3)$ & $4.4(3.9,5.6)$ & 0.026 \\
\hline GGT, IU/L & $58(34,90)$ & $52(44,68)$ & NS \\
\hline $\begin{array}{l}\text { Alkaline phosphatase, } \\
\text { IU/L }\end{array}$ & $91(57,146)$ & $130(96,237)$ & NS \\
\hline $\begin{array}{l}\text { Venous bicarbonate, } \\
\mathrm{mmol} / \mathrm{L}\end{array}$ & $22.4(20.1,23.7)$ & $21.6(18.8,24.2)$ & NS \\
\hline $\begin{array}{l}\text { Duration of } \\
\text { symptoms, days }\end{array}$ & $3(3,5)$ & $4(2,5)$ & NS \\
\hline Affected surface, $\%$ & $3(2,5)$ & $6(4,13)$ & 0.033 \\
\hline No. debridements & $3(3,4)$ & $4(3,5)$ & NS \\
\hline $\begin{array}{l}\text { Length of hospital } \\
\text { stay, days }\end{array}$ & $32(15,62)$ & $12(3,25)$ & NS \\
\hline FGSI score & $5(3,7)$ & $10(7,12)$ & 0.002 \\
\hline \multicolumn{4}{|c|}{$\begin{array}{l}\text { Min: minimum; max: maximum; bpm: beats per minute; rpm: breaths per minute; GGT: } \\
\text { gamma-glutamyl transpeptidase; FGSI score: Fournier's Gangrene Severity Index Score; } \\
\text { NS: nonsignificant ( } p>0.05) \text {. }\end{array}$} \\
\hline
\end{tabular}

Diabetes mellitus is the most common predisposing factor, but does not affect the prognosis and clinical outcome. ${ }^{19,20}$ The most common concomitant disease in our study was also diabetes $(38 \%)$, but it was not significantly related to mortality. Only the mortality rate in heart disease was significantly higher $(p=0.038)$, similar to reports by García Marín and Jiménez-Pacheco and their respective colleagues. ${ }^{6,17}$

Given the severity of symptoms and the rapid progression of necrosis, it is important to recognize Fournier's gangrene early, when cutaneous manifestations are minimal. Delay in surgical debridement can increase the extent of the necrosis, and lead to a worse prognosis. ${ }^{21,22}$ Early admission, rapid diagnosis, and adequate surgical treatment are crucial components in achieving a successful outcome. The median duration of symptoms before admission was a day longer in non-survivors (4 vs. 3), but this was not predictive for mortality in our study. Moreover, Chawla and colleagues reported that the number of surgical debridement negatively affected mortality since it might reflect a greater extent of disease. ${ }^{23}$ In our series, there were no differences regarding this parameter between survivors and non-survivors, consistent with other studies. $^{24-26}$ In contrast, we found that the extent of affected body surface was significantly higher in non-survivors than in survivors $(p=0.033)$, as confirmed in other studies. ${ }^{8,27}$

Consequently, we believe that the extent of necrosis is one of the most important prognostic factors in Fournier's gangrene. Furthermore, most authors advocate that intestinal diversion should be used in cases of colorectal perforation or anal sphincter involvement, or simply to prevent fecal contamination of the wound. In our study, diverting colostomy was done in 14 patients, but did not show any prognostic value. ${ }^{28,29}$ In addition, wound cultures were mostly polymicrobial in our patients, and the isolated microorganisms were not significantly different between survivors and nonsurvivors, concurrent with other reports. ${ }^{3,4}$

Some laboratory parameters, such as low levels of hematocrit and albumin, or high levels of urea, creatinine, leukocyte count, sodium, potassium, alkaline phosphatase and lactate dehydrogenase, have been shown to have a prognostic value. $^{4,6,13}$ In our study, mortality was significantly higher in patients with low levels of hemoglobin $(p=0.023)$ and hematocrit $(p=0.019)$, as well as elevated levels of serum urea $(p=0.009)$, creatinine $(p=0.042)$ and potassium $(p=0.026)$. These biologic disorders reflect renal dysfunction probably related to septic shock and may be the initial stage of a multiorgan failure. Reduced hemoglobin and hematocrit levels showed an altered general status in the patient. This alteration was also related to the sepsis from Fouriner's gangrene. In addition, severe sepsis on admission was also predictive for higher mortality in our patients $(p=0.027)$.

Laor and colleagues developed a prognostic index (FGSI) to determine the severity of infection and prognosis of patients with Fournier's gangrene, by using vital signs and laboratory data. ${ }^{5}$ In this system, a FGSI of 9 was used as a threshold parameter to predict outcome. FGSI $\geq 9$ had a $75 \%$ probability of death and FGSI $<9$ had a $78 \%$ probability of survival. The cut-off point and its predictive value have been validated in other current series. ${ }^{15,30}$ In our case, the FGSI was significantly higher in non-surviving patients with an acceptable discriminatory capacity $(p=0.002)$. Such results support the established threshold value of 9 and the validity of the FGSI. Recently, Yilmazlar and colleagues suggested a new scoring system, the Uludag FGSI (UFGSI), adding 2 parameters (age and disease extension) to the classic FGSI score. ${ }^{31}$

Based on the results of our study, we concluded that the use of a prognostic scoring system is important to identify patients with a greater risk of major complications or death. Extra attention is required to manage these patients. A more aggressive treatment with extensive surgical debridement, appropriate antibiotic and adequate fluid resuscitation should be started at admission. A careful follow-up must be performed in the intensive care unit to reduce mortality and to improve outcome.

Major limitations of this study include its retrospective design and small sample size, a common limitation due to 
Tarchouli et al.

the rarity of Fournier's gangrene. A multi-institutional prospective study is needed to accrue the number of patients necessary to further validate the prognostic factors of this entity.

\section{Conclusion}

Despite overall improvement in the antibiotic spectrum and surgical techniques, Fournier's gangrene continues to be a serious pathology with a high mortality rate. Early recognition of infection with prompt radical debridement is the mainstays of successful management. Comprehensive evaluation of metabolic status and physiological parameters, predisposing factors, and the extent of necrosis may help determine mortality risk and establish an optimal treatment. The FGSI score remains a simple and valid method to evaluate infection severity and predict outcome in patients with Fournier's gangrene.

Competing interests: The authors declare no competing financial or personal interests.

This paper has been peer-reviewed.

\section{References}

1. Fournier JA. Jean-Alfred Fournier 1832-1914. Gangrene foudroyante de la verge (overwhelming gangrene). Sem Med 1883. Dis Colon Rectum 1988:31:984-8.

2. Benjelloun el B, Souiki T, Yakla N, et al. Fournier's gangrene: Our experience with 50 patients and analysis of factors affecting mortality. World J Emerg Surg 2013;8:13. http://dx.doi.org/10.1186/17497922-8-13.

3. Altarac $S$, Katusin $D$, Crnica $S$, et al. Fournier's gangrene: Etiology and outcome analysis of 41 patients. Urol Int 2012;88:289-93. http://dx.doi.org/10.1159/000335507.

4. García Marín $A$, Turégano Fuentes $F$, Cuadrado Ayuso $M$, et al. Predictive factors for mortality in Fournier's gangrene: A series of 59 cases. Cir Esp 2015;93:12-7. http://dx.doi.org/10.1016/i. cireng.2014.03.013.

5. Laor E, Palmer LS, Tolia BM, et al. Outcome prediction in patients with Fournier's gangrene. J Urol 1995; $154: 89-92$

6. García Marín A, Martín Gil J, Vaquero Rodríguez A, et al. Fournier's gangrene: analysis of prognostic variables in 34 patients. Eur J Trauma Emerg Surg 2011;37:141-5. http://dx.doi.org/10.1007/ s00068-010-0028-7.

7. Tuncel $A$, Aydin 0 , Tekdogan $U$, et al. Fournier's gangrene: Three years of experience with 20 patients and validity of the Fournier's Gangrene Severity Index Score. Eur Urol 2006;50:838-43. http://dx.doi. org/10.1016/i.eururo.2006.01.030.

8. Yeniyol CO, Suelozgen $\mathrm{T}$, Arslan $\mathrm{M}$, et al. Fournier's gangrene: Experience with 25 patients and use of Fournier's gangrene severity index score. Urology 2004;64:218-22. http://dx.doi.org/10.1016/i urology.2004.03.049.

9. Aridogan $\mid A$, Izol V, Abat $D$, et al. Epidemiological characteristics of Fournier's gangrene: $A$ report of 71 patients. Urol Int 2012;89:457-61. http://dx.doi.org/10.1159/000342407.
10. Sorensen MD, Krieger JN, Rivara FP, et al. Fournier's gangrene: Management and mortality predictors in a population based study. J Urol 2009;182:2742-7. http://dx.doi.org/10.1016/i.juro.2009.08.050.

11. Eke N. Fournier's gangrene: A review of 1726 cases. Br J Surg 2000;87:718-28. http://dx.doi. org/10.1046/i.1365-2168.2000.01497.x.

12. Czymek R, Frank $P$, Limmer $S$, et al. Fournier's gangrene: Is the female gender a risk factor? Langenbecks Arch Surg 2010;395:173-80. http://dx.doi.org/10.1007/s00423-008-0461-9.

13. Corcoran AT, Smaldone MC, Gibbons EP, et al. Validation of the Fournier's gangrene severity index in a large contemporary series. J Urol 2008;180:944-8. http://dx.doi.org/10.1016/i.juro.2008.05.021.

14. Sorensen MD, Krieger IN, Rivara FP, et al. Fournier's gangrene: Population based epidemiology and outcomes. J Urol 2009;181:2120-6. http://dx.doi.org/10.1016/i.juro.2009.01.034.

15. Lujan Marco S, Budia A, Di Capua C, et al. Evaluation of a severity score to predict the prognosis of Fournier's gangrene. BJU Int 2010;106:373-6. http://dx.doi.org/10.1111/j.1464-410X.2009.09075.x.

16. Shyam DC, Rapsang AG. Fournier's gangrene. Surgeon 2013;11:222-32. http://dx.doi.org/10.1016/i. surge.2013.02.001.

17. Jimenez-Pacheco A, Arrabal-Polo MA, Arias-Santiago $S$, et al. Fournier gangrene: Description of 37 cases and analysis of associated health care costs. Actas Dermosifiliogr 2012;103:29-35. http://dx.doi. org/10.1016/i.adengl.2011.04.007.

18. Torremadé Barreda J, Millán Scheiding M, Suárez Fernández C, et al. Fournier gangrene. A retrospective study of 41 cases. Cir Esp 2010;87:218-23. http://dx.doi.org/10.1016/S2173-5077(10)70051-X.

19. Nisbet AA, Thompson IM. Impact of diabetes mellitus on the presentation and outcomes of Fournier's gangrene. Urology 2002;60:775-9

20. Yanar $H$, Taviloglu $K$, Ertekin $C$, et al. Fournier's gangrene: Risk factors and strategies for management. World J Surg 2006;30:1750-4. http://dx.doi.org/10.1007/s00268-005-0777-3.

21. Janane A, Haiii F, Ismail TO, et al. Hyperbaric oxygen therapy adjunctive to surgical debridement in management of Fournier's gangrene: Usefulness of a severity index score in predicting disease gravity and patient survival. Actas Urol Esp 2011;35:332-8. http://dx.doi.org/10.1016/i.acuro.2011.01.019.

22. Tuncel $A$, Keten $T$, Aslan $Y$, et al. Comparison of different scoring systems for outcome prediction in patients with Fournier's gangrene: Experience with 50 patients. Scand J Urol 2014;48:393-9. http://dx.doi.org $/ 10.3109 / 21681805.2014 .886289$

23. Chawla SN, Gallop C, Mydlo JH. Fournier's gangrene: An analysis of repeated surgical debridement. Eur Urol 2003:43:572-5.

24. Erol $B$, Tuncel $A$, Hanci $V$, et al. Fournier's gangrene: Overview of prognostic factors and definition of new prognostic parameter. Urology 2010;75:1193-8. http://dx.doi.org/10.1016/i.urology.2009.08.090.

25. Palmer $L S$, Winter $H I$, Tolia BM, et al. The limited impact of involved surface area and surgical debridement on survival in Fournier's gangrene. Br J Urol 1995;76:208-12.

26. Roghmann F, von Bodman C, Loppenberg B, et al. Is there a need for the Fournier's gangrene severity index? Comparison of scoring systems for outcome prediction in patients with Fournier's gangrene. BJU Int 2012;110:1359-65. http://dx.doi.org/10.1111/i.1464-410X.2012.11082.x.

27. Ruiz-Tovar J, Cordoba L, Devesa JM. Prognostic factors in Fournier gangrene. Asian J Surg 2012;35:37-41. http://dx.doi.org/10.1016/i.asjsur.2012.04.006.

28. Akcan A, Sozuer E, Akyildiz $H$, et al. Necessity of preventive colostomy for Fournier's gangrene of the anorectal region. Ulus Travma Acil Cerrahi Derg 2009;15:342-6.

29. Ozturk E, Sonmez Y, Yilmazlar T. What are the indications for a stoma in Fournier's gangrene? Colorectal Dis 2011;13:1044-7. http://dx.doi.org/10.1111/.1.1463-1318.2010.02353.x.

30. Oymaci E, Coskun A, Yakan S, et al. Evaluation of factors affecting mortality in Fournier's Gangrene: Retrospective clinical study of sixteen cases. Ulus Cerrahi Derg 2014;30:85-9. http://dx.doi. org/10.5152/UCD.2014.2512

31. Yilmazlar T, Ozturk E, Ozguc $\mathrm{H}$, et al. Fournier's gangrene: An analysis of 80 patients and a novel scoring system. Tech Coloprocto/2010;14:217-23. http://dx.doi.org/10.1007/s10151-010-0592-1.

Correspondence: Dr. Mohamed Tarchouli, Department of Digestive Surgery, Mohammed V Military Hospital, Rabat, Morocco; mtarchouli@gmail.com 